
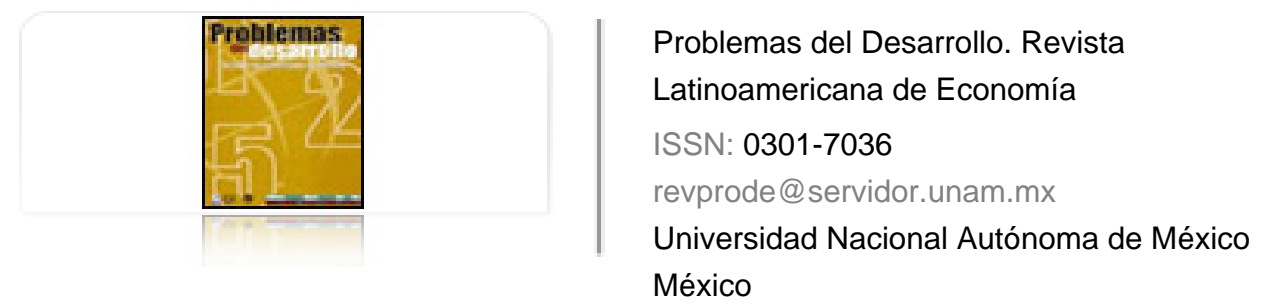

Paz, Raúl

Mitos y realidades sobre la agricultura familiar en Argentina: reflexiones para su discusión Problemas del Desarrollo. Revista Latinoamericana de Economía, vol. 39, núm. 153, abril-junio, 2008, pp. 57-82

Universidad Nacional Autónoma de México

Distrito Federal, México

Disponible en: http://www.redalyc.org/articulo.oa?id=11820161003

Cómo citar el artículo

- Número completo

- Más información del artículo

Página de la revista en redalyc.org

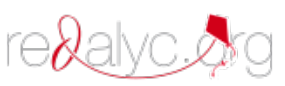

Sistema de Información Científica

Red de Revistas Científicas de América Latina, el Caribe, España y Portugal Proyecto académico sin fines de lucro, desarrollado bajo la iniciativa de acceso abierto 


\title{
MITOS Y REALIDADES SOBRE LA AGRICULTURA FAMILIAR EN ARGENTINA: REFLEXIONES PARA SU DISCUSIÓN
}

\author{
Raúl Paz*
}

Fecha de recepción: 3 de diciembre de 2007. Fecha de aceptación: 12 de marzo de 2008.

\section{Resumen}

La intensificación de la concentración de la tierra, los fuertes procesos políticos y sociales -encabezados por la Federación Agraria Argentina (FAA)—, los actuales debates sobre la pequeña agricultura europea, así como el papel activo de la pequeña producción en el desarrollo económico de Japón, Taiwán y Corea del Sur, entre otros, constituyen algunos de los variados fenómenos que alientan el interés por la agricultura familiar, especialmente en el campo de una nueva agenda de desarrollo rural en Argentina. En el debate sobre la agricultura familiar, suelen observarse miradas muchas veces contrapuestas sobre el tipo de apoyo que se debe darle y, en consecuencia, al desempeño que este sector debería cumplir en el desarrollo regional. En este artículo se plantean algunas reflexiones que giran alrededor de estas cuestiones, muchas veces presentadas en el abordaje académico como axiomas o dogmas.

Palabras clave: agricultura familiar, Censo Nacional Agropecuario 2002 (Argentina), desaparición de las explotaciones campesinas, potencial productivo y eficiencia campesina.

* Investigador del CONICET y docente de la Universidad Nacional de Santiago del Estero, Argentina. Correo electrónico: pazraul@unse.edu.ar. 


\section{Summary}

The intensified concentration of land, powerful political and social processes-headed by the Argentine Agrarian Federation (FAA) -current debates about small-scale European agriculture, as well as the active role of small production in economic development in Japan, Taiwan and South Korea, among other countries, constitute some of the various phenomena promoting an interest in family farming, especially in the context of a new agenda for rural development in Argentina. In the debate on family farming, we often used to see opposed views on the type of support it should be given and, as a consequence, on the role this sector should play in regional development. The present study makes a number of reflections that turn on these questions, often presented in the academic approach as axioms or dogmas.

Key words: family farming, National Farm Census, 2002 (Argentina), disappearance of rural exploitation, productive potential, small farm efficiency.

\section{Résumé}

L'intensification de la concentration de la propriété de la terre, les forts processus politiques et sociaux - impulsés par la Fédération Agraire Argentine (FAA) -, les actuels débats sur les petits agrigulteurs européens et sur le rôle actif de la petite production dans le développement économique du Japon, de Tä̈wan et de Corée du Sud, entre autres, constituent quelques uns des divers phénomènes qui stimulent l'intéret pour l'agriculture familiale, notamment dans le cadre d'un nouvel agenda de déverloppement rural en Argentine. Dans le débat sur l'agriculture familiale, il est courant d'observer des points de vue souvent opposés quant au type d'aide qu'il faut lui donner et, par conséquent, sur le rôle que ce secteur devrait jouer dans le développement régional. Cet article expose quelques réflexions sur ces questions par ailleurs souvent abordées selon l'approche académique à travers axiomes et dogmes.

Mots clés: agriculture familiale, Recensement Agricole National 2002 (Argentine), disparition des exploitations paysannes, potentiel productif et efficacité paysanne.

\section{Resumo}

A intensificação da concentração da terra, os fortes processos políticos e sociais encabeçados pela Federação Agrária Argentina (FAA), os atuais debates sobre a pequena agricultura européia, bem como o papel ativo da pequena produção no desenvolvimento econômico do Japão, Taiwan e Coréia do Sul, entre outros, constituem alguns dos variados fenômenos que alentam o interesse pela agricultura familiar, especialmente no campo de uma nova agenda de desenvolvimento rural na Argentina. No debate sobre a agricultura familiar, é comum observar-se miradas muitas vezes contrapostas sobre o tipo de apoio que se deve dar a esse tipo de economia e, em consequiência, ao desempenho que este setor deveria cumprir no desenvolvimento regional. Neste artigo se colocam algumas reflexões que giram ao redor destas questões, muitas vezes apresentadas na abordagem acadêmica como axiomas ou dogmas.

Palavras-chave: agricultura familiar, Censo Nacional Agropecuário 2002 (Argentina), desaparecimento das explotações camponesas, potencial produtivo e eficiência camponesa. 


\section{Introducción}

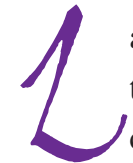

a renovada y creciente atención en torno a la agricultura familiar en Argentina, como en gran parte de los países latinoamericanos, es un fenómeno reciente. Desde la denominación de agricultura familiar se encuadran distintos actores sociales agrarios que fueron conceptualizados en momentos diferentes y en contextos regionales y de formaciones sociohistóricos diversas.

En el término "agricultura familiar" convergen figuras sociales como el pequeño productor, el minifundista, el campesino, el chacarero, el colono, el productor familiar y también los campesinos y productores rurales sin tierra, así como las comunidades de pueblos originarios (extraído del Documento del Foro Nacional de la Agricultura Familiar, 2006:4).

A primera vista, el factor que aglutina a estos diversos actores sociales es la presencia de estrechos lazos familiares y el aporte de trabajo — tanto al proceso productivo como al de gestión de la explotación—, sobre todo proporcionado por la familia. ${ }^{1}$

La intensificación de la concentración de la tierra —y en consecuencia la distribución de la renta agraria - en estas últimas décadas constituye uno de los principales procesos que ha revitalizado esta perspectiva. Datos de la Federación Agraria Argentina (2005) dan cuenta de ello: "74.3 millones de hectáreas (de un total de 170 millones) están en poder de tan sólo 4 mil dueños; es decir que el 1.3\% de los propietarios hoy posee el 43\% de la superficie" (FAA, 2005:69). En este acelerado proceso de concentración ha sido afectado el campesino ubicado en las regiones extrapampeanas, pero también y con mucha mayor intensidad el colono, el chacarero ofarmer que está distribuido sobre todo en la región pampeana.

En la esfera de lo político-institucional, la agricultura familiar comienza a tener un viso de reconocimiento y legitimidad a partir de los fuertes procesos políticos y sociales, encabezado fundamentalmente por la FAA y la Secretaría de Agricultura,

1 Como referencia, vale la pena citar la definición de agricultura familiar correspondiente a la Plataforma Tecnológica Regional sobre Agricultura Familiar del PROCISUR en tanto se trata de una definición discutida entre equipos técnicos oficiales de los países del MERCOSUR y asociados: "La Agricultura Familiar es un tipo de producción donde la Unidad Doméstica y la Unidad Productiva están físicamente integradas, la agricultura es la principal ocupación y fuente de ingreso del núcleo familiar, la familia aporta la fracción predominante de la fuerza de trabajo utilizada en la explotación, y la producción se dirige al autoconsumo y al mercado conjuntamente" (extraído del Documento del Foro Nacional de la Agricultura Familiar, 2006:5). 
Ganadería, Pesca y Alimentos (SAGPYA), en conjunto con los distintos movimientos campesinos y algunos programas nacionales orientados al apoyo de la pequeña producción (Márquez, 2007).

Así lo expresan distintos acontecimientos como la creación del Foro Nacional de la Agricultura Familiar que comenzó a sesionar a inicios del año 2005. Después, en un encuentro realizado en agosto de 2006 en Parque Norte (Buenos Aires), donde participaron más de 1,800 representantes de numerosas organizaciones del campo, se generaron los lineamientos sobre políticas públicas orientadas al diseño de un plan estratégico para la agricultura familiar. Por otro lado, en el ámbito regional, en el MERCOSUR comienzan a funcionar las reuniones especializadas de agricultura familiar (REAF) con presencia de autoridades de los ministerios de agricultura de Brasil, Paraguay, Uruguay y Argentina.

También en 2006 se edita en el marco de la Secretaría de Agricultura, Ganadería, Pesca y Alimentación un documento que pretende cuantificar, a partir del Censo Nacional Agropecuario de 2002, a los pequeños productores en Argentina y dimensionar su peso económico y laboral (Obschatko et al., 2006).

Este renovado interés por la agricultura familiar en algunos países de América Latina, ${ }^{1}$ en especial en Argentina, coincide con los debates contemporáneos europeos (Van der Ploeg, 2003 y 2004), en los cuales las nociones de agricultura campesina o la diversidad existente en los distintos estilos de producción están reemergiendo como elementos claves para comprender los distintos procesos que están ocurriendo en el mundo rural europeo. También es coincidente con los trabajos orientados a países como China, Corea del Sur o Taiwán, entre otros, donde a partir de dichos estudios comienza a conocerse el papel que jugó la agricultura campesina ${ }^{2}$ en el desarrollo económico de las naciones asiáticas (Bryceson et al., 2001; Griffin et al., 2002; Kay, 2002 y 2006; Bramall, 2004).

Por otro lado, la crisis del modelo de producción empresarial que se pone de manifiesto en el deterioro ambiental, el excesivo consumo de energía no renovable, la forma de apropiación y redistribución de los beneficios, la incapacidad de generar fuentes

2 Recientemente en Brasil se editó un libro muy interesante como resultado del Primer Coloquio de Agricultura Familiar y Desarrollo Rural, donde se presenta una cantidad de estudios referentes a la diversidad de la agricultura familiar. Véase Schneider (2006).

3 Un dato curioso extraído de Ortega (1992) es que en 1860 Bélgica tenía 84\% de explotación con menos de tres hectáreas. En Holanda el promedio de la explotación agrícola en 1880 no alcanzaba 1.2 hectáreas. Algo similar ocurrió en Corea, Japón o Taiwán a partir de 1940 con las grandes reformas (Kay, 2002 y 2006). 
de trabajo y un despoblamiento acentuado en el campo (agricultura sin agricultores), entre otros, hace pensar en la necesidad de búsquedas de prácticas de desarrollo opcionales más cuidadosas del ambiente, de la producción de valor y de su redistribución.

Por lo antes expuesto, la agricultura familiar en Argentina está comenzando a ser materia de políticas públicas. Ya desde la dimensión académico-científica se hace necesario acompañar a este proceso con la búsqueda de reflexiones sobre las bases teóricas y conceptuales que sustentan a este tipo de producción. En el actual debate sobre la agricultura familiar, suelen observarse miradas muchas veces contrapuestas acerca del tipo de apoyo que se debe darle, y en consecuencia, al papel que este sector debería cumplir en el desarrollo económico de la región.

En este artículo se plantean algunas reflexiones que giran alrededor de la pequeña agricultura, muchas veces presentadas como axiomas o dogmas que expresan el inmenso poder del pensamiento mítico sobre la realidad campesina y que suelen perfilar un modelo conceptual preestablecido que se proyecta en el mundo científico y caracteriza el presente para determinar el futuro.

\section{Primera reflexión: el inexorable proceso de concentración y desaparición de las pequeñas explotaciones agropecuarias}

Las tendencias de las economías más maduras y desarrolladas del mundo señalan para este último siglo un fuerte proceso de desaparición de las explotaciones agropecuarias (EAP). Por nombrar sólo algunos países, Francia muestra en las pasadas tres décadas una caída de cerca de 54\% que representa alrededor de 830,000 explotaciones. Alemania para el mismo periodo (1970-1995) denota una disminución de casi 500,000 explotaciones, es decir, $47 \%$ del total. Italia, país donde menos disminuyeron, muestra una caída de 367,800 explotaciones, que representa sólo $12.9 \%$. Procesos similares se dan en Estados Unidos (EU), donde en el mismo periodo analizado desaparecen 818,391 explotaciones (Azcuy, 2005).

En el marco de esta tendencia global, son tres los fenómenos que guardan una estrecha relación con respecto a la visión sobre la desaparición de las explotaciones agropecuarias.

El primero está vinculado con un proceso de desaparición continuado, es decir que para diferentes periodos siempre hubo una caída del total de las explotaciones agropecuarias, sin importar el contexto histórico, político, económico y social.

Un estudio en el agro alemán (Van der Ploeg, 2003) señala que la reducción neta promedio de las explotaciones agropecuarias es de -1.7\% anual para el periodo 1990-1997, 
donde se observa que ha disminuido levemente en relación con el periodo 1970-1975 y 1975-1980, que exhibe valores de $-2.2 \%$ y $-2.1 \%$, en cada caso.

Del trabajo de Azcuy (2005), en el que presenta datos sobre la evolución de las explotaciones agropecuarias para cinco países europeos (Alemania, Francia, Italia, Holanda e Inglaterra) para el periodo 1970-1995, también se puede concluir que dicho proceso ha sido continuado. La variación neta promedio ha oscilado entre valores de $0.25 \%$ anual y de $-3.14 \%$, según el periodo que se esté analizando. Algo similar se observa para Estados Unidos, donde en el periodo 1940-1997 desaparecieron más de cuatro millones de explotaciones agropecuarias con una tasa anual de perdida que va entre $-0.2 \%$ y $-4.4 \%$.

Argentina no constituye la excepción. En el cuadro 1 se compara la información proveniente del último Censo Nacional Agropecuario de 2002 (CNA 2002) con el anterior realizado en 1988 (CNA 1988), donde se observa que la caída del número de explotaciones agropecuarias alcanzó $21 \%$ en todo el país, lo cual equivale a cerca de 90,000 explotaciones (Lazzarini, 2004).

Cuadro 1 Número de explotaciones, superficie promedio por explotación (en hectáreas) y variación porcentual según regiones

\begin{tabular}{lrrrrrr}
\hline Región & $\begin{array}{c}\text { EAP } \\
\text { CNA 7988 }\end{array}$ & $\begin{array}{c}\text { EAP } \\
\text { CNA 2002 }\end{array}$ & Var \% & $\begin{array}{r}\text { Sup. media } \\
\text { CNA 7988 }\end{array}$ & $\begin{array}{c}\text { Sup. media } \\
\text { CNA 2002 }\end{array}$ & Var \% \\
\hline Cuyo & 46,222 & 37,959 & $-18 \%$ & 148.9 & 198.0 & $33 \%$ \\
NEA & 85,249 & 70,036 & $-18 \%$ & 246.6 & 301.2 & $22 \%$ \\
NOA & 72,183 & 67,373 & $-7 \%$ & 395.9 & 393.3 & $-1 \%$ \\
Pampeana & 196,254 & 138,828 & $-29 \%$ & 395.6 & 533.2 & $35 \%$ \\
Patagonia & 21,313 & 17,726 & $-17 \%$ & $3,746.4$ & $4,127.1$ & $10 \%$ \\
Total país & 421,221 & 332,057 & $-21 \%$ & 469.0 & 587.7 & $25 \%$ \\
\hline
\end{tabular}

NEA: noreste argentino

NOA: noroeste argentino

Fuente: $\mathrm{Paz}(2006 \mathrm{a})$.

El segundo punto en consideración es que tal desaparición se concentra en la franja de las explotaciones familiares con escasa extensión de tierra. Nuevamente si uno recurre a los datos utilizados por Azcuy (2005) se observa que para Francia en el periodo 1970-2000 las explotaciones que se encuentran por debajo de las 50 hectáreas de superficie han caído en $68 \%$ en contraposición con aquellas que se encuentran por arriba de dicha línea, las cuales han crecido sustancialmente. Si se toma el caso de 
Iowa (EU) para el periodo 1987 y 2002, también se observa una disminución de más de $40 \%$ de aquellas explotaciones que se encuentran ubicadas en el rango de entre 50 y 200 hectáreas (Azcuy, 1998).

Argentina también continúa con esa tendencia para las explotaciones con menor superficie. Así, el informe de la Dirección de Economía Agraria (2003) de la SAGPYA muestra en el periodo 1988-2002 —y en aquellas explotaciones que están por debajo de las 500 hectáreas- la desaparición de cerca de $18 \%$ del total de los establecimientos agropecuarios y una disminución de $20 \%$ del total de superficie explotada. Por otro lado, el tamaño promedio de las explotaciones creció de 469 hectáreas en 1988 a 588 hectáreas en 2002, es decir, $25 \%$ para el total del país, lo que muestra un aumento en la ampliación de las escalas de producción.

El tercer aspecto, ya más orientado a la construcción conceptual que se deriva del análisis de la información censal presentada (tendencia mundial), es sobre las transformaciones operadas en la agricultura argentina en estas últimas dos décadas. La disposición de capital para mantenerse dentro del proceso productivo se ha elevado considerablemente y ello se manifiesta de manera clara en el aumento de la superficie promedio por explotación que está asociada a los incrementos de las escalas de producción para los distintos tipos de cultivos. Relacionada a ello se encuentra la desaparición de las explotaciones más pequeñas en contraposición con el aumento de las más grandes, que muestra un proceso donde se profundiza la concentración del capital en el agro.

Desde el análisis de la información censal para los países más desarrollados así como para Argentina, la sensación final es que tanto el actual proceso de globalización, como el nuevo modelo agroalimentario y la liberalización de la economía en general están produciendo grandes cambios estructurales en el agro y van configurado una nueva ruralidad donde predominan etapas no agrarias y más urbanizadas (Martínez, 1999 y 2004). Ello suele expresarse muchas veces en el marco de una tendencia general de deterioro de la pequeña agricultura para América Latina (Tapella 2002; Kay, 2001).

\section{Segunda reflexión: la falacia sobre la desaparición del campesino en Argentina: un abordaje cuantitativo}

El proceso de desaparición de las explotaciones más pequeñas, como tendencia general, constituye un rasgo bastante común de la lógica de desarrollo del capitalismo agrario tanto en el ámbito internacional como en Argentina. Se puede suponer entonces que la desaparición de las pequeñas explotaciones en Argentina se encuentre 
fuertemente correlacionada con la eliminación de las explotaciones campesinas. Una mirada hacia dos estructuras agrarias dispares, como la región pampeana y la del noroeste argentino (NOA), permitirá contrastar esa hipótesis (Paz, 2006a).

Salvo las diferencias que separan al capitalismo estadounidense, francés o alemán — todos ellos maduros y centrales — del capitalismo dependiente y periférico — vigente en Argentina—, se puede llegar a pensar que el agro pampeano orientado hacia la exportación de granos y carnes no está demasiado distante del existente en las economías centrales, especialmente si se consideran sus procesos de trabajo, los niveles de producción y productividad, su competitividad internacional y la infraestructura presente, entre otros. ${ }^{4}$

A partir de dicha similitud y siguiendo la misma tendencia, no es casual entonces observar que la región pampeana presenta los mayores niveles de desaparición de explotaciones agropecuarias $(57,426)$, lo que explica el $64 \%$ en relación con el total de todo el territorio nacional. La superficie media para dicha región pasó de 395.6 hectáreas (ha), según el CNA 1988 a 533.2 ha para el CNA 2002, con un incremento de $35 \%$ (Lazzarini, 2004).

También se observa una gran caída en el estrato de hasta 500 hectáreas (-34\% en cantidad de EAP y $-26 \%$ en superficie ocupada por este estrato) y los mayores aumentos se registran en los estratos de 2,500 a 10,000 hectáreas ( $+6 \%$ en cantidad de EAP y $+5 \%$ en superficie) y de más de $10,000(+13 \%$ en cantidad de EAP y $+14 \%$ en superficie). ${ }^{5}$

Con base en lo anterior, la tradicional hipótesis de la desaparición de las pequeñas explotaciones familiares en la región pampeana es un hecho.

Para la región NOA "la penetración del capitalismo es escasa y lenta, y su difusión en el conjunto de actividades locales es insuficiente y pasiva, con excepción de producciones bien acotadas y puntuales de vigorosa dinámica" (Manzanal, 1995:72).

El NOA presenta la menor variación (7\%) con respecto a las otras regiones, en cuanto a los descensos de explotaciones agropecuarias, y explica sólo 5\% (4,810 explotaciones) del total de los establecimientos desaparecidos en Argentina. Por el contrario, la región pampeana interpreta 64\%, con una disminución de 57,426 estableci-

4 Azcuy (1998) en su trabajo "La evolución histórica de las explotaciones agropecuarias en la Argentina y Estados Unidos: los casos de Pergamino y Iowa, 1888-1988" toma como áreas similares para el análisis de las transformaciones agrarias a Pergamino (Argentina) con Iowa (Estados Unidos).

5 Procesos similares se observan en las provincias que componen la región pampeana. Véase (Román y Robles (2004 y 2005) y Hocsman y Preda (2005). 
mientos. Por otro lado, la superficie media de la región NOA se mantuvo prácticamente constante (395.9 y 393.3 hectáreas, para el CNA 1998 y 2002, en cada caso).

Al menos son tres las razones para que la región NOA, desde su estructura agraria, sea más llamativa y diferente con respecto a las otras, y más aún al compararla con la región pampeana.

La primera está asociada al gran peso que tienen las pequeñas explotaciones con respecto al total. Con datos del CNA 1988, Basco (1993) establece para el NOA que $72 \%$ de las mismas pertenece a explotaciones minifundistas.

Para Santiago del Estero — una de las provincias que comprende a esta regiónse determinó la cantidad de explotaciones campesinas (Paz, 2006a) en un número de 14,321 según el CNA 1988 y de 14,215 para el CNA 2002, lo que representa $67.80 \%$ del total de las EAP. En el mismo trabajo ${ }^{6}$ se concluye que el número de explotaciones campesinas prácticamente se ha mantenido constante para el periodo intercensal definido. El siguiente cuadro muestra lo antes expuesto.

Cuadro 2

Número de explotaciones campesinas, discriminada por límites definidos y sin definir y variación porcentual sobre la base del CNA 1998 y 2002 para la provincia de Santiago del Estero

\begin{tabular}{lrrr}
\hline Tipos de explotaciones para Santiago del Estero & \multicolumn{3}{c}{ Total EAP } \\
\cline { 2 - 4 } & CNA 88 & CNA 02 & Var \% \\
\hline Explotaciones Agropecuarias Totales (EAP) & 21,122 & 20,949 & -0.82 \\
EAP campesinas con límites definidos & 4,992 & 4,096 & -17.5 \\
EAP campesinas sin límites definidos & 9,329 & 10,119 & 8.47 \\
EAP campesinas totales & 14,321 & 14,215 & -0.07 \\
\% EAP campesinas con respecto al total & 67.80 & 67.80 & 0.00 \\
\hline
\end{tabular}

Fuente: Paz (2006a)

El segundo aspecto y tal vez resulte el más interesante, en cuanto a un nuevo actor social agrario, es la presencia de un tipo de explotación que poco tiene qué ver con el campesino latinoamericano y da la idea de la diversidad de los sujetos sociales agrarios en el continente.

6 Lamentablemente no existen trabajos de esta naturaleza para las distintas provincias que comprenden las regiones extrapampeanas, a los efectos de establecer la posible disminución de este tipo de explotaciones. 
Uno de los aspectos más relevantes de estos dos últimos censos agropecuarios (1988 y 2002) con respecto al anterior (CNA 1969) es la utilización de un cuestionario especial orientado a relevar la información referida a las explotaciones agropecuarias sin límites definidos. ${ }^{7}$ La aplicación de dicha metodología permitió reconocer dentro de la estructura agraria argentina a un nuevo sujeto social que no estaba previsto en las estadísticas vinculadas con la problemática rural hasta esos momentos: el campesino ubicado en explotaciones sin límites definidos, el cual está fuertemente asociado a la condición de campesino ocupante (Paz, 1995a; 1995b y 1996), campesino con ánimo de dueño (de Dios et al., 1998) o puestero criollo (Camardelli, 2003). La ocupación precaria de tierras privadas o fiscales de la población rural todavía sigue siendo un problema generalizado en las provincias del noroeste argentino, y en menor proporción en otras regiones. Para el caso del NOA son 24,806 explotaciones sin límites definidos, ${ }^{8}$ mientras que para la región pampeana sólo 766, según el CNA de 2002.

Desde el punto de vista cuantitativo, los campesinos que viven en explotaciones sin límites definidos son importantes al representar cerca de 37\% del total de la estructura agraria del noroeste argentino. Al comparar los datos que arrojan los censos analizados se observa para la región un crecimiento de las explotaciones sin límites, tanto en términos absolutos (1,599 explotaciones) como en términos relativos con respecto al total de explotaciones agropecuarias $(2.13 \%)^{9}$ (Paz, 2006b).

El sector de los campesinos ubicados en las explotaciones sin límites definidos, lejos de desaparecer, en estas últimas décadas muestra un leve aumento en el NOA.

La tercera razón y es la que invita a pensar y reflexionar sobre la estructura agraria y el desarrollo capitalista en el agro, especialmente cuando se presenta en ella una proporción importante de explotaciones campesinas, es la propia dinámica de penetración capitalista que se ve reflejada en la desaparición y concentración de las explotaciones

7 Las explotaciones sin límites definidos suelen localizarse dentro de áreas más extensas caracterizadas por el régimen jurídico (ocupantes, derechosos, arrendamientos y sin discriminar). A los fines censales estas áreas con explotaciones sin límites se denominan unidades mayores y son los campos comuneros, comunidades indígenas, parques o reservas nacionales, tierras fiscales o privadas (INDEC, 1992).

8 Las explotaciones sin límites definidos no tienen alambrado perimetral, algo muy común entre campesinos que sólo mantienen un cerco de ramas para la actividad agrícola y hacen pastar sus animales a monte.

9 En Paz (2006b) “¿Desaparición o permanencia de los campesinos ocupantes en el Noroeste Argentino? Evolución y crecimiento en la última década" hay un análisis exhaustivo de estas explotaciones. También se presentan algunas consideraciones metodológicas en la cuantificación del sector campesino para Argentina. 
agropecuarias. La permanencia actual del campesino en la región del noroeste argentino no se puede explicar sólo a partir de la intensificación del proceso de penetración capitalista. Tampoco se puede caer en la simplificación de pensar que cuando el capitalismo se manifieste de forma más vigorosa, deba hacerlo necesariamente de manera similar a como se presentó en otras regiones como la pampa húmeda.

La región del NOA es muy distinta a la pampeana. Su diferencia está en el mismo origen de la configuración de la estructura agraria; en las grandes extensiones y marginalidad de sus tierras asociadas a la situación jurídica irregular de las mismas; en el predominio de formas de tenencia distintas a las de apropiación privada; en mercados de trabajo donde la cultura feudal y la del patronazgo están fuertemente arraigadas; en la presencia de un sistema informal de comercialización para muchos productos agropecuarios y del monte (cabritos, llamas, vicuñas, quesos, artesanías, chacinados, cultivos aromáticos, carbón, leña, postes, etcétera); en el fuerte componente de autoconsumo y redes de solidaridad ${ }^{10}$ entre las explotaciones y sus miembros; en los procesos productivos extensivos y tradicionales con escasa o nula incorporación de tecnología como también con un nivel bajo de inversión, entre otros.

Allí el campesino y la pequeña producción encuentran intersticios donde desarrollar sus modelos productivos, dentro de sus propias estrategias de sobrevivencia y donde el capitalismo aún no ha descubierto la forma de introducirse y ser competitivo en el escenario que le impone la región del NOA.

\section{Tercera reflexión: descubriendo el potencial productivo de la agricultura familiar y su capacidad de generar desarrollo en el espacio rural}

Desde una mirada acotada a los campesinos sin límites definidos del noroeste argentino se pueden llegar a explorar algunos procesos en cuanto a la persistencia y su potencial productivo. Cuando se analiza el aporte productivo agrícola en la región NOA, se observa que dicha participación es ínfima. De 1,084,052 hectáreas cultivadas, sólo 1.77\% proviene de las explotaciones indeterminadas según el CNA de 1988, que al compararse con el de 2002 dichos aportes disminuyen aún más con sólo $0.7 \%$ del total de superficie cultivada.

10 Es interesante analizar el trabajo de Neiman et al. (2004) donde se presentan numerosos casos de redes familiares y sociales que se generan en los sectores más pobres en el mundo rural. 
Sin embargo, al analizar el cuadro 3, acerca del número de cabezas para distintas especies animales, según las explotaciones agropecuarias con y sin límites definidos, se observa en primera instancia una presencia significativa de animales y, en segundo lugar, un incremento en la cantidad de ellos al comparar ambos censos.

Cuadro 3

Distribución del número de cabezas por especies y tipo de explotaciones agropecuarias según los Censos Nacionales Agropecuarios de 1988 y 2002 para la región del NOA

\begin{tabular}{lccccc}
\hline Especies pecuarias & $\begin{array}{c}\text { Núm. cabezas } \\
\text { EAP } \\
\text { s/limite }\end{array}$ & $\begin{array}{c}\text { Núm. Cabezas } \\
\text { EAP } \\
\text { c/limite }\end{array}$ & Total cabezas & $\begin{array}{c}\text { \% participación } \\
\text { de EAP } \\
\text { s/limite }\end{array}$ & $\begin{array}{c}\text { Núm. cabezas } \\
\text { EAP s/lim. } \\
\text { Diferencia } \\
\text { 2002-1988 }\end{array}$ \\
\hline Camélidos CNA 1988 & 96,735 & 132,525 & 229,260 & 42.19 & \\
Camélidos CNA 2002 & 116,139 & 38,259 & 154,398 & 75.22 & 19,404 \\
Caprinos CNA 1988 & 752,104 & 363,925 & $1,116,029$ & 67.39 & \\
Caprinos CNA 2002 & 988,011 & 502,660 & $1,490,671$ & 66.28 & 235,907 \\
Bovinos CNA 1988 & 459,696 & $1,689,910$ & $2,149,606$ & 21.39 & \\
Bovinos CNA 2002 & 561,234 & $1,545,340$ & $2,106,574$ & 26.64 & 101,538 \\
Ovinos CNA 1988 & 697,118 & 417,089 & $1,114,207$ & 62.57 & \\
Ovinos CNA 2002 & 604,483 & 291,703 & 896,186 & 67.45 & $-92,635$ \\
Total NOA CNA 1988 & $2,005,653$ & $2,603,449$ & $4,609,102$ & 43.52 & \\
Total NOA CNA 2002 & $2,269,867$ & $2,377,962$ & $4,647,829$ & 48.84 & 264,214 \\
\hline
\end{tabular}

Fuente: $\mathrm{Paz}(2006 \mathrm{a})$.

Para las especies caprinas y bovinas ubicadas en las explotaciones sin límites se observa un crecimiento considerable en el número de animales, mientras que en la ovina hay un decrecimiento importante. Aquí se manifiesta claramente un fortalecimiento de la producción pecuaria sobre todo para aquellas especies que tienen un carácter mercantil.

De los datos expuestos en párrafos anteriores, se desprende la idea de que en esta última década hubo un incremento en el número de las explotaciones campesinas sin límites definidos en la región del noroeste argentino asociado al aumento de las especies pecuarias con una disminución de la producción agrícola.

En trabajos recientes sobre estudios de casos orientados a estos sistemas de producción, se concluye que para las localidades de Atamisqui (Paz, 1995a; Paz y colab., 2002), Ojo de Agua (Castaño, 2003), Quebrachos (Paz et al., 2000; Paz y colab. 2002) y de Dios (2006), todas ubicadas en la provincia de Santiago del Estero, 
la contracción de un mercado laboral estacional (migraciones estacionales), producto de la mecanización de las tareas agrícolas en zonas más desarrolladas, ha generado una profundización de los lazos de sobrevivencia y de intercambio. El autoconsumo está limitado fundamentalmente al de origen animal, sobre todo de especies menores (cerdos, aves y especies silvestres), quedando restringidos los ingresos monetarios a la venta de animales provenientes de las especies bovinas y caprinas principalmente. Camardelli (2003) en su trabajo, luego de un análisis profundo y exhaustivo, concluye que "los puesteros criollos del lote fiscal 20 en particular y los de la región del Chaco Salteño semiárido en general, han aprendido a convivir y producir, aprovechando recursos ambientales fuertemente restrictivos" (p. 245), y continúa diciendo que dichos productores aumentaron sus ingresos prediales globales, que si bien a algunos no les alcanza para la reproducción de la unidad familiar; a otros les queda un saldo para atender la reproducción de la unidad, pero manteniendo un comportamiento de bajo nivel de inversión en lo predial productivo.

En consecuencia, este sector más allá de desaparecer o debilitarse, construye una conducta defensiva donde el manejo y el uso del recurso pecuario constituyen su principal basamento. El papel de la ganadería en las economías campesinas es un tema que, aunque conocido (Quijandría, 1987; González de Olarte, 1987; Orskov y Viglizzo, 1994), aún no se ha logrado desarrollar un corpus teórico sobre ella. Ríos Osca (1992: p. 81) señala: "El aporte de la ganadería en las economías campesinas es 'una realidad todavía sin teoría'."

Desde una mirada más amplia, el trabajo de Obschatko et al. (2006) determina un total de 218,868 explotaciones agropecuarias que comprenden al sector de la agricultura familiar, es decir, cerca de $66 \%$ del total de explotaciones de Argentina. La participación de los pequeños productores en la generación de cultivos extensivos es de $16 \%$, de frutales de $17 \%$, de cultivos intensivos a campo de $36 \%$, de forestales de $14 \%$ y de productos pecuarios de $21 \%$, aproximadamente. Por otro lado, al cuantificar el aporte de empleo total (permanente y transitorio con contratación directa) en el ámbito nacional, se observa en el mismo trabajo valores de $53 \%$. En provincias como Santiago del Estero, Misiones y Catamarca se encuentran valores de $85 \%$ para las dos primeras y de $79 \%$ para Catamarca.

Los datos provenientes de los trabajos anteriormente citados muestran no sólo la capacidad productiva de los sistemas tradicionales extensivos ubicados en áreas de secano, sino una agricultura familiar con un fuerte potencial productivo y una intensa articulación con el mercado como oferente de la producción, refutando así la 
hipótesis de la falta de recursos para producir y de pobreza extrema. Considerar a la agricultura familiar como un sector estratégico en el desarrollo local exige, en un primer momento, reconocer su importancia cuantitativa y de permanencia en el marco del sistema capitalista derivado de su propia lógica interna, para luego demostrar su capacidad productiva.

\section{Cuarta reflexión: algunas consideraciones sobre la eficiencia en la pequeña producción: pocos estudios de casos en Argentina}

Una de las principales características presentes en la agricultura familiar, y que la hace diferente a las explotaciones de corte capitalista, es la conformación de una unidad económica familiar donde el trabajo de sus propios miembros no suele ser asalariado y donde se conjuga la unidad de producción con la unidad doméstica (Chayanov, 1974). Es allí donde el salario, como categoría económica en el sentido moderno, está claramente ausente. En la doctrina económica de la sociedad capitalista moderna, el precio, los salarios, el interés y la renta son categorías económicas funcionalmente dependientes. Parafraseando a Chayanov (1987:54), “[...] si un elemento de construcción de este sistema se cae, el edificio entero se hunde. En ausencia de cualquiera de estas categorías económicas, todas las demás pierden su carácter específico y su contenido conceptual".

Así los dos paradigmas dominantes de los estudios económicos campesinos, el marxista y el neoclásico, han mostrado dificultades al momento de pretender medir la eficiencia campesina.

El marxismo - cuya hipótesis principal es que la pobreza campesina proviene de la extracción de excedentes por el propio sistema capitalista a partir de relaciones asimétricas impuestas en los distintos mercados- centra su atención en cuestiones más bien de tipo macroeconómico. Desde esa perspectiva pretende analizar las connotaciones básicas del funcionamiento de la organización social capitalista desde una contingencia histórica de larga duración. Es difícil entonces encontrar en la teoría marxista herramientas adaptables a estudios microeconómicos y estáticos (Kervyn, 1987). No obstante, en los “campesinistas" existen esfuerzos ideológico-conceptuales (y muy pocas pruebas empíricas) tendentes a probar la eficiencia ${ }^{11}$ que tienen en

11 Para una mayor profundización en esta temática véase Lehmann (1985), de Janvry (1982), Vergopoulos (1978), Bernstein (1979), entre otros. 
común de que tanto la productividad de la tierra y el capital están basados en el uso intensivo y de bajo costo de la mano de obra familiar.

Por otro lado, está el paradigma neoclásico que intenta probar la eficiencia de la agricultura tradicional (llámese campesina). Así Schultz (1967), uno de los principales exponentes de esta escuela de pensamiento, plantea como esquema preliminar " [...] que la agricultura tradicional presenta los rasgos inequívocos de un equilibrio económico consolidado, en cuanto al ahorro, la inversión y la producción" (Schultz, 1982:40).

Entonces, sobre este esquema se derivan dos hipótesis económicas que son fundamentales para comprender el comportamiento de los trabajadores del campo en la agricultura tradicional. La primera se sintetiza en la conocida frase de "eficiente pero pobre" (Schultz, 1967:35), hipótesis utilizada por Schultz (1967 y 1982) y otros autores (Yotopoulos y Nugent, 1976), donde buscan probar, y así lo hacen, que los escasos recursos a disposición de los agricultores tradicionales son utilizados con gran eficiencia, inclusive con más que en la agricultura moderna. La segunda, tan interesante como la primera pero menos conocida y difundida en los estudios económicos campesinos, es el débil incentivo de los agricultores tradicionales para aumentar la producción como consecuencia de tasas de rendimiento de la inversión muy bajas.

Schultz (1982), al hablar de prueba de aplicación de factores, está indicando “[...] la capacidad para conseguir el volumen de producción óptimo a partir de una cantidad dada de determinados factores productivos" (p. 58) y expresa llanamente el concepto de eficiencia ${ }^{12}$ técnica. Para demostrar tal eficiencia se basa en los trabajos de Sol Tax y de David Hopper sobre comunidades agrícolas campesinas de Guatemala e India, respectivamente.

El entramado teórico neoclásico se sustenta $-\mathrm{y}$ es allí donde radica su principal debilidad - en el criterio unívoco de racionalidad asociado al objetivo comprendido por el aumento de una función de utilidad, restringida en específico al crecimiento de las ganancias (Astori, 1984).

Sin embargo, uno de los principales aportes de la teoría neoclásica, a mi juicio, radica en el hecho de ubicar al campesino como un sujeto eficiente y apartar las apreciaciones subjetivas que consideran que los trabajadores rurales están encerrados en

12 "En la agricultura tradicional existen relativamente pocas ineficiencias en cuanto a la distribución de los factores productivos entre sus diversas aplicaciones posibles" (Schultz, 1967:33). 
una cultura tradicional, guiados sólo por las costumbres, y cuyas actitudes constituyen el principal freno al desarrollo y modernidad de la agricultura (Kervyn, 1987).

En 2004 se publicó, en un número especial de la revista Journal of Agrarian Change, una discusión sobre la reforma de la tierra, tocando de forma directa la eficiencia de la pequeña producción con respecto a la gran explotación capitalista. En ese número se puede observar a defensores (Griffin, 2002 y 2004) y detractores (Byres 2004a y 2004b) sobre la eficiencia de la pequeña producción campesina en distintos contextos y espacios. Para Griffin et al. (2002 y 2004) es factible pensar, sobre la base del éxito de las reformas agrarias, en los países asiáticos (Taiwán, Japón, Corea del Sur, China y Vietnam), en un modelo de crecimiento económico a partir de la creación de un sistema de explotaciones campesinas y su eficiencia en el uso de los recursos productivos.

Esta breve revisión de los principales pensamientos sobre la pequeña producción muestra que el debate sobre la cuestión de la eficiencia campesina presenta fundamentos teóricos y empíricos particularmente confusos y variados. En varios de estos trabajos el concepto de eficiencia y el de productividad ${ }^{13}$ han sido tomados como sinónimos.

Tal vez, todo ello pueda explicar en parte la escasa cantidad de trabajos técnicoacadémicos en estas décadas pasadas para América Latina, y más aún para Argentina sobre la eficiencia campesina, especialmente al relativizarlos con la vasta y nutrida bibliografía relacionada a la cuestión campesina en general. Uno de los pocos trabajos, si no el único en Argentina —aún inédito—, que busca determinar la eficiencia campesina en contraste con las empresas capitalistas, es el de Rodríguez et al. (2007). En él se aplica una técnica de programación matemática, denominada análisis envolvente de datos (DEA), que permite calcular el índice de eficiencia técnica a un grupo de establecimientos lecheros caprinos compuestos por explotaciones campesinas y pequeñas empresas familiares y capitalistas, ubicadas en el área de riego de la provincia de Santiago del Estero. Los resultados preliminares de dicho trabajo muestran un nivel de eficiencia técnica global para la cuenca lechera de 59.5\%, conformado por una eficiencia técnica pura de $72.1 \%$ y una eficiencia de escala de $81.4 \%$.

Una de las cuestiones más debatidas entre los economistas agrarios vinculados con el desarrollo rural ha sido, y continúa siendo, si las explotaciones capitalistas

13 La productividad sólo se refiere a la parte productiva, mientras que el de eficiencia incorpora al análisis la dimensión maximizadora del beneficio (Porter, 1980; Coelli, 1998). La eficiencia juega un papel fundamental en el marco de competitividad, pues para ser competitivo no se trata de alcanzar una elevada productividad, sino de lograr que con un nivel de productividad determinado se obtenga el máximo beneficio posible (Álvarez Pinilla, 2001). 
modernas (intensivas en capital, escalas de producción y altamente especializadas) son más eficientes que las explotaciones más tradicionales que comprenden el sector que se le ha dado el nombre genérico de agricultura familiar (intensivas en el uso de la mano de obra familiar, bajos niveles de inversión y estrategias que buscan bajar los costos monetarios a partir de la disminución de insumos externos a las explotaciones).

\section{Quinta reflexión: la desaparición de la agricultura campesina como precondición para el desarrollo de la agricultura: la ruptura de un mito}

El proceso de desaparición de las pequeñas explotaciones familiares en la región pampeana es un hecho. El mismo es esperable y se reafirma al ser interpretado dentro

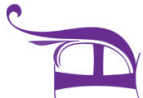
de la propia tendencia mundial de la penetración del capitalismo en el agro, donde - desde un enfoque estrictamente evolucionista- las explotaciones con lógicas productivas distintas a la clásica producción capitalista tienden a ser concebidas como un estadio en el proceso del desarrollo, como una situación transicional que tenderán en algún momento hacia su transformación. Las explotaciones familiares y campesinas entonces deben necesariamente pasar a otro estadio. Ésta es la premisa básica que suele ser transferida, sin mucho análisis, en la comprensión de los procesos de transformación social de la pequeña producción en cualquier lugar del mundo.

Tres son las proposiciones sobre la cual descansa esta mirada. La primera que está presente en esta perspectiva - y que raramente suele ser explicitada — es la presencia de una fuerza conductora del desarrollo capitalista con una direccionalidad específica (Djurfeldt, 1999). Por tanto, existe un esfuerzo conceptual por considerar al campesino de la globalización (una etapa histórica del capitalismo) como un producto final de dicho proceso; es decir, un campesino que si aún no se ha transformado, va hacia su propia transformación de la mano del capitalismo: de campesino a proletario rural o urbano, a semiproletario, a empresa familiar capitalizada o - desde una mirada posmodernista - de campesino a polybians (Kearney, 1996).

La segunda —entendida desde la lógica del modelo del desarrollo capitalista en el agro- lleva a pensar que las mismas causas provocarán siempre los mismos efectos. Es entonces más que esperable que la penetración del capital en sus distintas formas (complejos agroindustriales, concentración de la propiedad, megaempresas, desarrollo de innovaciones tecnológicas y de infraestructura básica, entre otros) genere una instancia de destrucción y, por ello, de desaparición de las explotaciones de menor escala y, por tanto, del sector campesino. 
El modelo de acumulación no puede ser generalizable a toda la sociedad concreta, y menos aún a la rural, en un momento determinado de la historia. Existe un sinnúmero de actores sociales agrarios o de estilos de producción que surgen por la múltiple maleabilidad de la agricultura y de las formas de combinar en las explotaciones los recursos que ella presenta. ${ }^{14}$

Sin embargo, no se puede llegar a desconocer que hay una tendencia estructural en el mundo agrario capitalista, con lógicas de funcionamiento conocidas y a las que los estudiosos de las ciencias sociales suelen echar mano al momento de interpretar los procesos de la sociedad rural.

La tercera preposición gira más alrededor de la visión académica y conceptual de la agricultura familiar y del campesinado. El desarrollo agrario, y más precisamente la historia agraria, ha sido entendido como un proceso continuo de mercantilización, como una inevitable progresión, una tendencia unilineal, desde la economía natural hacia la mercantilización completa de tal economía. Es sobre esta línea argumentativa que la desaparición del campesinado ha sido predicada por décadas y vista como un estadio intermedio del desarrollo agrícola. Otro proceso que corre de forma paralela es la constante ampliación de las escalas de producción en las explotaciones — a costa de las más pequeñas — como una estrategia para la sobrevivencia. El proceso de modernización puede ser imaginado como la transformación de las explotaciones a un nuevo óptimo con ampliación de escala y más intensiva en capital, como elementos claves para el logro de la competitividad.

Lo que en primera instancia fue planeado como una predicción, con el tiempo pasó a ser un proceso inevitable y afianzado desde la retórica conceptual, resultado del desarrollo tecnológico (determinismo tecnológico) y de las leyes del mercado (determinismo de mercado) (Van der Ploeg, 2003).

Es común escuchar a técnicos y estudiosos del mundo rural hablar de la modernización como un proceso necesario e inevitable, del éxodo rural y la caída de las fuentes de trabajo en el sector agropecuario como un daño colateral de la propia ampliación de escala y de la modernización. A estos axiomas se les suele unir otros, muchas veces de manera implícita en el discurso de académicos y políticos:

14 Van der Ploeg (2003) define tal flexibilidad a partir de tales condicionantes: a) variadas condiciones ecológicas, b) variadas combinaciones en un sentido técnico entre trabajo, objetos de trabajo y herramientas, c) el proceso de trabajo y sus diversas formas de distribuirlo en las distintas tareas agrícolas y no agrícolas, d) los caprichos de la naturaleza como sequía, inundaciones, etcétera. 
- El grupo de las grandes explotaciones capitalistas constituye el sector vital del desarrollo agrícola.

- Los niveles de alta competencia sólo se pueden lograr por la ampliación de escala, especialmente con la incorporación más intensiva de capital y al aumentar la productividad del trabajo (o al reducir la mano de obra) con nuevas tecnologías.

- La disminución de las explotaciones — sobre todo de las pequeñas y tradicionales (campesinas) — es considerada una señal de progreso. Pero en caso de que desaparezcan las pequeñas explotaciones capitalistas ${ }^{15}$ - y más aún de las grandes, las llamadas eficientes-comienza a presentarse un problema y una profunda preocupación.

Estos axiomas, que por ser evidentes no necesitan ser testeados o discutidos, han ido generado y después imponiendo un modelo conceptual con un orden preestablecido en el presente y, en consecuencia, un ordenamiento explícito del futuro. Así una realidad agraria virtual al igual que un agricultor, producto de un diseño de gabinete que el de una realidad concreta, ha sido creada desde la retórica conceptual que se traduce muchas veces en la producción de la ignorancia para el tema campesino (Van der Ploeg 1994 y 2003).

Así, por ejemplo, la real significancia del aporte de las economías campesinas como del sector que comprende la agricultura familiar es fuertemente subestimada por los sistemas institucionalizados de registros de datos para el sector (por ejemplo, el Instituto Nacional de Estadística y Censo), existiendo un gran desconocimiento al respecto. Dos ejemplos, por sólo dar algunos, pueden clarificar mejor este concepto.

1. Al momento de pretender cuantificar al sector campesino, a partir de los censos nacionales agropecuarios, suele presentarse la primera dificultad relacionada con la ausencia de variables precisas que pueden discriminar ${ }^{16}$ a las explotaciones

15 La desaparición de un número de explotaciones capitalistas en la región pampeana generó una profunda preocupación que se materializó en los planteos de la Federación Agraria, dirigida principalmente hacia la agricultura familiar.

16 Del trabajo de Paz (2006a:p. 74) se desprenden algunas consideraciones en relación con estos aspectos. "La agricultura campesina puede llegar a formularse conceptualmente, pero al momento de llevarlo a un ejercicio práctico, como es su cuantificación para un ámbito geográfico regional o nacional utilizando información censal, suele presentar ciertos niveles de complejidad, sobre todo al tratar de establecer los límites entre los distintos sujetos sociales agrarios que componen el mundo rural. Desde el rango de tamaño, la categoría de campesino queda cristalizada y reducida a una dimensión, determinada principalmente por la 
campesinas de otros tipos de éstas, menos aun cuando se quiere determinar el aporte de la producción de este sector. En la actualidad una de las principales preocupaciones de los estudiosos de la problemática de la pequeña producción en Argentina es la definición de los límites de la agricultura familiar a partir de los datos censales, sobre todo entre la explotación agrícola familiar y la pequeña y mediana empresa capitalista. La precisión de estas definiciones, en cuanto a los actores sociales agrarios que componen el campo argentino, permitirá la concreción de atinadas políticas públicas para el sector.

2. Las regiones del noroeste y noreste argentino tienen en su estructura agraria cerca de $70 \%$ de pequeños productores que presentan un cierto dinamismo en su producción; sin embargo, y pese a su importancia cuantitativa, aún no se han desarrollado registros censales y contables acordes para captar tal dinámica.

\section{Reorientación de la visión sobre la agricultura familiar}

Mucho se ha escrito sobre el campesinado (menos sobre la agricultura familiar) en Argentina. La mayoría de estos trabajos giran en torno a una caracterización de un tipo social agrario asociado a un carácter pasivo, alrededor de sus estrategias de reproducción dentro de una perspectiva de pobreza y en un contexto de relaciones asimétricas con el sistema económico actual. Los estudios tendentes a captar el propio estilo de producción, las prácticas y lógicas involucradas en dicho estilo, las formas de combinar los recursos y sus articulaciones con los mercados, tratando de identificar su potencial en el marco de un desarrollo opcional, han sido menos estudiadas y hasta a veces dejada de lado.

En una analogía con el campesino polibians de Kearney (1996), se podría decir que la agricultura familiar en general —y el campesino en particular- es una bacteria muy especial. En el mundo de las bacterias existen dos categorías bien definidas: las bacterias aeróbicas por excelencia, que son altamente eficientes en presencia de altas concentraciones de oxígeno pero que ante su ausencia mueren, y

superficie de la explotación. En consecuencia los procesos de transformación social adoptan una secuencia lineal, donde una mayor proporción de tierra está asociada a la emergencia de una burguesía agraria materializada en una empresa capitalista o, por el contrario, una pequeña dotación conduce a la proletarización rural. Igual análisis es para la variable origen $y$ destino de la fuerza de trabajo donde nuevamente desde lo conceptual aparece una perspectiva unilineal al modificarse la cantidad y el tipo de mano de obra, llevando inevitablemente a los campesinos a trabajadores asalariados o viceversa". 
bacterias aeróbicas facultativas, que en un medio con oxígeno funcionan menos eficientemente que las anteriores, pero que ante su carencia siguen teniendo actividad. El campesino es una bacteria aeróbica facultativa que aprendió a sobrevivir en un medio sin capital, donde empresas capitalistas mueren (aeróbicas por excelencia) y el campesino sobrevive (Paz, 2006a).

Por otro lado, aquellos que participamos en la construcción y transferencia del conocimiento, ya sea desde las ciencias agropecuarias o desde las ciencias humanas, conformamos también el grupo de las bacterias aeróbicas por excelencia y nos sentimos claramente identificados con dicho sector (las empresas capitalistas). Esta empatía, que queda definida como la capacidad de ponerse en el lugar del otro, surge a partir del conocimiento profundo que se tiene de las empresas capitalistas: conocemos sus problemas y en consecuencia tenemos la solución técnico-administrativa para superarlos.

Por el contrario, en el marco de una formación aeróbica por excelencia, resulta difícil comprender los distintos mecanismos desplegados por la agricultura familiar, a los efectos de poder desarrollarse en un escenario carente o escaso de oxígeno (capital). La ciencia agraria convencional, en sí misma, también es aeróbica por excelencia y en sus modelos siempre están presentes leyes económicas o funciones de producción donde existen relaciones precisas entre los factores de producción y sus resultados (siempre medido en rendimientos y producción). ${ }^{17}$ Así aparece el punto óptimo económico o el punto de equilibrio, como también un camino determinado por las funciones de producción, en dirección a lograr la mayor eficiencia. Esta construcción virtual, este determinismo tecnológico, hace abstracción de variados y diversos estilos de producción donde la total mercantilización, la articulación absoluta con los mercados y la combinación "adecuada" de los factores de producción no se expresan con la magnitud esperada.

Es por ello que aquellos procesos de campesinización desde una combinación diferente a las propuestas tecnológicas derivadas de las funciones de producción, la resistencia campesina a partir del distanciamiento a los mercados o la intensificación de formas autónomas de producción, de búsquedas de adaptación y generación de nuevas oportunidades de crecimiento endógeno por parte de la agricultura familiar —donde las pequeñas explotaciones llegan a demostrar su capacidad de sobreponerse al embate de la lógica capitalista—, frecuentemente son historias que no son

17 Es interesante leer el ejemplo de la función de producción y su relación entre la fertilización nitrogenada y la producción de forraje en "The virtual farmer" (Van der Ploeg, 2003). 
tomadas en cuenta y no relatadas o estudiadas en profundidad, pues trastornan y alteran la ilusión del orden o la proyección de un futuro organizado de antemano, donde prevalecerá siempre la explotación capitalista (Van der Ploeg, 2003 y 2004). En esa percepción académico-científica resulta más fácil encontrar un marco conceptual que explique la desaparición de las pequeñas explotaciones o de la agricultura familiar, que el final de las grandes explotaciones capitalistas en el actual mundo globalizado.

Por otro lado, como bien se ha podido demostrar en párrafos anteriores, existe un importante potencial productivo en la agricultura familiar argentina, sobre todo en la región del noroeste argentino. La pobreza entonces no está en la falta de recursos productivos, sino más bien en un problema de gestión y reorientación de tales recursos. No se puede dejar de reconocer que la pobreza rural está asociada a una estructura agraria bimodal y a formas de producciones tradicionales, pero también a extensas superficies de tierra ${ }^{18}$ (en especial, las de monte) y a una fuerte pecuarización (desarrollo de la producción pecuaria), aspectos íntimamente ligados entre sí, y que constituyen la base de resguardo y permanencia de una parte muy importante de la agricultura familiar.

Este sello es lo que la hace prácticamente única a la región del noroeste argentino (como también a la del noreste) en la estructura agraria latinoamericana, y le da una impronta muy particular con respecto a la ruralidad de las viejas sociedades industriales y que hace difícil poder copiar el modelo seguido por ellas, en cuanto al papel que debería tener el medio rural y sobre todo el sector campesino en el desarrollo económico.

Ello lleva a pensar que una propuesta de desarrollo regional debe prever una nueva perspectiva acerca del territorio y de la diversidad de estilos de producción generados dentro del mismo. Allí entonces se hace necesaria la fuerte inclusión de forma activa de los actores sociales agrarios tradicionales (los campesinos), en donde la diversidad cultural, económica y formas de producir se constituyan más que en un problema a resolver a partir de políticas asistencialistas, en un nuevo estilo de desarrollo que hay que potenciar, con el incremento de su eficiencia y al ampliar sus efectos positivos en el entorno. Sin embargo, para ello hay que modificar la valoración que se tiene del espacio rural, dejándolo de considerar como una categoría residual frente a lo moderno y urbano.

18 A partir de datos obtenidos por fotointerpretación digital (Mariot, 2005), se puede estimar para la provincia de Santiago del Estero en 17 millones de hectáreas para las 10,000 explotaciones sin límites definidos. 


\section{Bibliografía}

Álvarez Pinilla, A. (comp.), La medición de la eficiencia y la productividad, Madrid, Ediciones Pirámide, 2001.

Astori D., Controversias sobre el agro latinoamericano. Un análisis crítico, Buenos Aires, CLACSO, 1984.

Azcuy Ameghino, Eduardo, "La evolución histórica de las explotaciones agropecuarias en la Argentina y Estados Unidos: los casos de Pergamino y Iowa, 1888-1988", en Realidad Económica, núm. 159, Buenos Aires, IADE, 1998, pp. 119-132.

,"La evolución del capitalismo agrario y la desaparición de explotaciones agropecuarias: evidencias estadísticas en países seleccionados y problemas de teoría e historia", en IV Jornadas Interdisciplinarias de Estudios Agrarios y Agroindustriales, Buenos Aires, 2005, 20 pp.

Basco, Mercedes, Hacia una estrategia de desarrollo rural para la Argentina, Buenos Aires, IICA, 1993.

Bernstein, H., "African Peasantries: A Theorical Framework", en Journal of Pesant Studies, núm. 6, 1979.

Bramall, Chris, "Chinese Land Reform in the Long-Run Perspective and in the Wider East Asian Context", Journal of Agrarian Change, 4 (1 y 2): 107-41, 2004.

Bryceson, D., Kay, C. y Mooij, J., Disappearing peasantries? Rural labour in Africa, Asia and Latin America, England, ITDG Publishing, 2001.

Byres, Terence J., "Introduction: Contextualizing and Interrogating the GKI Case for Redistributive Land Reform", Journal of Agrarian Change, 4, 2004a.

, "Neo-Classical Neo-Populism 25 Years On: Déjà Vu and Déjà Passé. Towards A Critique", Journal of Agrarian Change, 4 (1 and 2), 2004b.

Camardelli, Cristina, Estrategias reproductivas y sustentabilidad de sistemas ganaderos criollos del Chaco Salteño, tesis de maestría en Desarrollo Rural en Zonas Áridas y Semiáridas, Salta, Argentina. Universidades Nacionales del NOA, 2003.

Castaño, Lastenio, Parámetros técnico-productivos para la estimación de la oferta comercial de cabritos, en sistemas caprinos cabriteros tradicionales de Santiago del Estero, tesis de grado para optar al título de ingeniero agrónomo, Facultad de Agronomía y Agroindustria, Santiago del Estero, 2003.

Chayanov A., La organización de la unidad económica campesina, Buenos Aires, Nueva Visión, 1974.

, "Sobre la teoría de los sistemas económicos no capitalistas", en Chayanov y la teoría de la economía campesina, México, Cuadernos del Pasado y Presente, 1987.

Coelli, T. J, Prasada Rao, D. S. y G. E. Battese, An Introduction to Efficiency and Productivity Analysis, Kluwer Academic Publishers, 1998.

De Janvry, Alain, The Agrarian question in Latin America, Baltimore, John Hopkin University Press, 1982.

De Dios, Rubén, Diagnóstico sobre los pequeños productores, trabajadores transitorios y Pymes empobrecidas y grupos vulnerables de la Provincia de Santiago del Estero, Argentina, Documento Consultoría Proinder, 2006.

y otros, "Sistemas productivos y organización campesina", en Tasso, Paz y otros (eds.), Tipologías y vida campesina, Santiago del Estero, Barco Edita, 1998.

Djurfeldt, Göran, "Essentially non-peasant? Some critical comments on post-modernist discoursse on the peasantry”, en Revista Sociología Ruralis, vol. 39 (2), núm. 2, 1999.

Federación Agraria Argentina, La tierra, para qué, para quiénes y para cuántos: por una agricultura con agricultores, Buenos Aires, Ciccus, 2005.

Foro Nacional de la Agricultura Familiar, $L i$ neamientos generales de políticas públicas orientadas a la elaboración de un plan estratégica para la agricultura familiar, documento, Buenos Aires, 2006.

González de Olarte, Efraín, La lenta modernización de la economía campesina, Lima, Instituto de Estudios Peruanos, 1987.

Griffin, Keith, Azizur Rahman Khan y Amy Ickowitz, "Poverty and the Distribution of Land", Journal of Agrarian Change, vol. 2, núm. 3, 2002.

, "In Defence of Neo-Classical NeoPopulism", Journal of Agrarian Change, vol. 4, núm. 3, 2004.

Hocsman, Luis Daniel y Preda, Graciela, "Desarrollo agrario, estructura parcelaria y 
economía familiar en la provincia de Córdoba", en IV Jornadas Interdisciplinarias de Estudios Agrarios y Agroindustriales, Buenos Aires, 2005, 20 pp.

INDEC, Resultado General del Censo Nacional Agropecuario 1988, Provincia de Santiago del Estero, Buenos Aires, Documento núm. 25, 1992.

, Resultado General del Censo Nacional Agropecuario 2002, Provincia de Santiago del Estero, Buenos Aires, 2002.

Kay, Cristóbal, "Latin American Peasantries", en Bryceson, D., Kay, C. Y Mooij, J., Disappearing peasantries?, Rural labour in Africa, Asia and Latin America, Inglaterra, ITDG Publishing, 2001.

, "Why East Asia Overtook Latin America: Agrarian Reform, Industrialization and Development", Third World Quarterly, 23 (6): 1073-102, 2002.

"Una reflexión sobre los estudios de pobreza rural y estrategias de desarrollo en América Latina", en Revista Alasru, núm. 4, Chapingo, 2006.

Kearney, M., Reconceptualizing the Peasantry: Anthropology in Global Perspective, Boulder, Westview Press, 1996.

Kevryn, Bruno, La economía campesina en el Perú: teorías y políticas, Segundo Seminario Permanente de Investigación Agraria (SEPIA II), Cusco, Centro Bartolomé de las Casas, 1987.

Lazzarini, Andrés, "Notas sobre los primeros resultados del Censo Nacional Agropecuario 2002", en Revista Interdisciplinaria de Estudios Agrarios, núm. 20, Buenos Aires, PIEA, 2004, pp. 117-126.

Lehmann, David, "Two paths of agrarian capitalism: a critique of Chayanovian Marxism", Revista de Estudios Andinos, vol. III, núm. 7, Perú, 1985.

Manzanal, Mabel, "Globalización y ajuste en la realidad regional argentina: ¿reestructuración o difusión de la pobreza?", en Revista Realidad Económica, núm. 134, Argentina, IADE, 1995.

Mariot, V., Bases para el ordenamiento del uso de la tierra. En Santiago del Estero, una mirada ambiental, Santiago del Estero, UNSEFacultad de Ciencias Forestales, 2005.

Márquez, Susana, Un año de foro: crónica, realizaciones y perspectivas del ejercicio de diálogo político desarrollada por el Foro Nacional de la Agricultura Familiar, Buenos Aires, 2007.
Martínez, Luciano, "La nueva ruralidad en Ecuador: siete tesis para el debate", en Iconos, núm. 8, Ecuador, 1999.

"El campesino andino y la globalización a fines de siglo (una mirada sobre el caso ecuatoriano)", Revista Europea de Estudios Rurales Latinoamericanos y del Caribe, núm. 77, Ámsterdam, 2004.

Murmis, Miguel, "Temas en la sociología rural latinoamericana: reestructuración, desestructuración y problemas de excluidos e incluidos", en Revista Ruralia, núm. 5, Buenos Aires, FLACSO, 1994.

, "Agro argentino: algunos problemas para su análisis", en Giarraca, N. y Cloquell, S., Las agriculturas del MERCOSUR. El papel de los actores sociales, Buenos Aires, Ed. La Colmena, CLACSO, 1998.

Neiman, G., Blanco, M. y Jiménez, D., "Desde abajo. La participación de las redes familiares y sociales en la subsistencia de los sectores rurales pobres", en Floreal Forni (comp.), Caminos solidarios de la economía argentina. Redes innovadoras para la integración, Buenos Aires, CICCUS, 2004.

Obschatko, E., Foti, M. y Román, M., Los pequeños productores en la República Argentina. Importancia en la producción agropecuaria y en el empleo en base al CNA 2002, Serie Estudios e Investigaciones, núm. 10, Argentina, IICA, 2006.

Ortega, E., "La trayectoria rural de América Latina y el Caribe", en Revista CEPAL, núm. 47. Santiago de Chile, CEPAL, 1992.

Orskov y Viglizzo, The role of animals in spreading farmer's risks: a new paradigm for animal sciencie, Outlook on Agriculture, vol. 23, 1994.

Paz, Raúl, "Estructura agraria en la provincia de Santiago del Estero: los campesinos ocupantes. Algunas Pautas para su Desarrollo", en Realidad Económica, núm. 132, Buenos Aires, IADE, 1995a.

, "Degradación de recursos en economías rurales empobrecidas en el noroeste argentino", en Revista Debate Agrario, núm. 22, Lima, CEPES, 1995b.

"Los campesinos ocupantes en el noroeste argentino: una realidad para conocer”, en Revista Meridiano, núm. 2, Buenos Aires, Fundación Humboldt, 1996.

et al., "Parámetros técnico-productivos y tipologías en los sistemas caprinos tradicionales en áreas de secano", Revista Archivos Latinoamericanos de Producción 
Animal, vol. 8, núm. 2, Maracaibo, Alpa, 2000.

et al., Los sistemas de producción caprinos en Santiago de Estero. Proyección y desafíos para el desarrollo del sector, editor responsable Fundapaz, Tucumán, Universidad Nacional de Tucumán, 2002.

,"El campesinado en el agro argentino: ¿repensando el debate teórico o un intento de reconceptualización?", en Revista Europea de Estudios Latinoamericanos y del Caribe, núm. 81, Ámsterdam, CEDLA, $2006 a$.

, ¿Desaparición o permanencia de los campesinos ocupantes en el noroeste argentino? Evolución y crecimiento en la última década", en Canadian Journal of Latin American and Caribbean Studies, vol. 31, núm. 61, Canadá, 2006b.

,El campesino en Santiago del Estero: la pobreza de un sector que se resiste a desaparecer, inédito, 2007.

Porter, Michael, Competitive Strategy, Nueva York, Free Press, 1980.

Quijandría, Benjamín, Las explotaciones pecuarias en los hogares rurales en el Perú: importancia y articulación con el desarrollo agrario, Lima, Fundación Friedrich Ebert, 1987.

Rodríguez, Ramiro; Paz, Raúl y Robledo, Walter, Estudio de Eficiencia Económicoproductiva en la cuenca lechera caprina de Santiago del Estero, inédito, 2007.

Ríos Ocsa, Benicio, Ganadería y economía campesina. La importancia de los animales en los sistemas tradicionales de producción en la Sierra Sur de Cusco, Cusco, Centro de Estudios Regionales Andinos Bartolomé de las Casas, 1992.

Román, Marcela y Robles, Daniel, “Avances y retrocesos de las explotaciones familiares. Algunos datos y nuevos cuestionamientos para la provincia de Buenos Aires", en $I V$ Jornadas Interdisciplinarias de Estudios Agrarios y Agroindustriales, Buenos Aires, 2005, 22 pp.

Schneider, Sergio, A diversidade da agricultura familiar, Brasil, UFRGS, 2006.

Schultz, Theodore W., Transforming Traditional Agriculture, New Haven, Yale University Press, 1964.

, "On the Economics of Agricultural Production over Time", Economic Inquiry, Oxford University Press, vol. 20 (1), 1982.

Tapella, Esteban, Reformas estructurales y la cuestión agraria en Argentina: reabriendo el debate entre "chayanovistas" y "leninistas" al inicio del nuevo siglo, ponencia presentada en el VI Congreso Latinoamericano de Sociología Rural, Porto Alegre, Universidad Federal de Río Grande del Sur, 2002.

Van der Ploeg, Jan, "Born from within", en Ann Long, Assen (ed.), Practice and perspectivies of endogenous rural development, Van Gorcum, 1994,

, The virtual farmer. Países Bajos, Royal Van Gorcum, 2003.

, Seeds of transition, Países Bajos, Royal Van Gorcum, 2004.

Vergopoulos, Kostas, "Le Capitalisme Difforme", en S. Amin and K. Vergopoulos (eds.), La Question Paysanne et Le Capitalisme, París, Editions Anthropos, 1978. 
Anexo

Mapa 1

Explotaciones sin límites definidos para las distintas regiones de Argentina

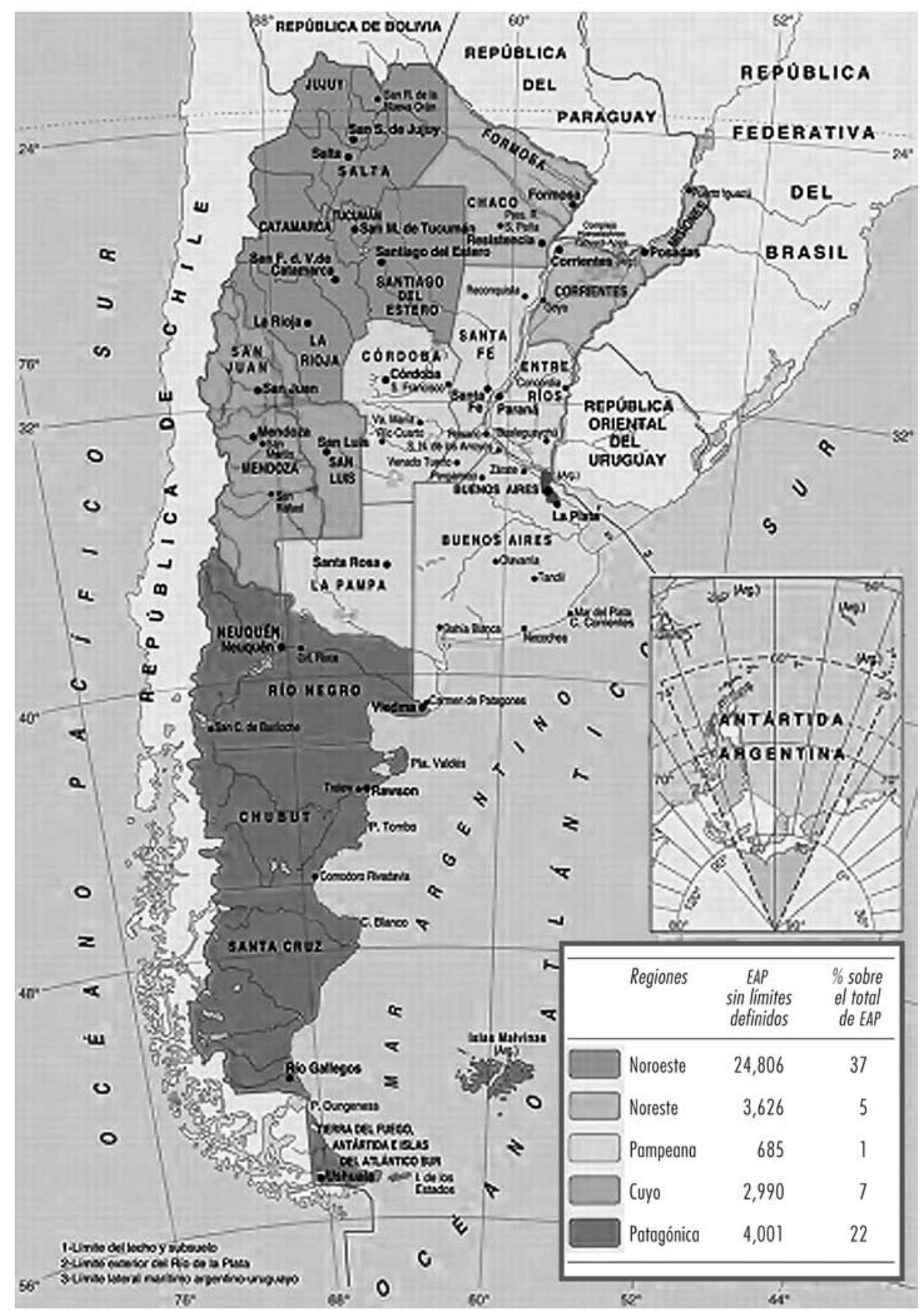

Este mapa forma parte del corpus del artículo enviado por el autor. 